\title{
On the Complexities of the Tax Law
}

\author{
Hideki SATO*
}

\begin{abstract}
The aim of this note is to show the implications of tax law complexity concerning the parties who face a tax dispute. While the tax auditor tries to prevent tax evasion and to ensure that taxpayers pay the right amount of tax, there are times when the auditor and the taxpayer do not agree on what legal amount of tax is. As the result of analyzing this situation in which a taxpayer and an auditor interact strategically, the divergence between the amount of tax increases through the complex of the law and, with the complexity, the parties can agree on what amount of a revised return is.
\end{abstract}

\section{Introduction}

One of the well-known pioneering works on economic analysis of tax evasion is that of Allingham and Sandmo [1]. This seminal paper modeled the evasion of income tax as if it were adding one more risky asset to a taxpayer's portfolio and analyzed the effects of the audit probabilities and fine levels in deterring tax evasion. While this approach has traditionally incorporated into economic analysis, the facts that many taxpayers comply more fully than is predicted by this approach have been pointed out (Andreoni, Erand and Feinstein [2]).

To explain this, we will mention that the manner in which parties resolve their tax disputes have an effect on the cost of noncompliance. In this note, we will derive two results: (1) while the tax auditor tries to prevent tax evasion and to ensure that taxpayers pay the right amount of tax, there are times when the auditor and the taxpayer do not agree on what legal amount of tax is, and (2) as the result of analyzing this situation in which a taxpayer and an auditor interact strategically, the divergence between the amount of tax increases through the complex of the law and, with the complexity, the parties can agree on what amount of a revised return is.

In next section, we consider the effect of the complexity in a simultaneously-move game between a taxpayer and an auditor and examine a numerical example. Finally, we conclude the implication of tax law complexity.

\section{Tax Dispute Resolution}

\subsection{The Resolution of Tax Disputes}

The resolution of tax disputes in Japan is summarized as follows. When the contents shown on the tax return are inconsistent with the findings of an audit, tax office can amend a taxpayer's selfassessment (General law of national taxes article, hereafter Article; 24). In this case, the tax office must send the taxpayer a notice of correction specifying the contents of the correction and the reasons. Then, there are two ways in which a taxpayer can object to an assessment imposed by the tax office: administrative protest and litigation (Article 75 and 85). In principle, litigation must be filed with national tax tribunal and cannot be pursued until all administrative protests have been finished (Article 115). Next, we will summarize the basic model of tax dispute.

\footnotetext{
* Kyushu-Sangyo University
} 


\subsection{The Model of Tax Disputes}

Our model has the same underlying structure as Gibbons [3] with the addition of dispute costs. Consider a taxpayer who calculates the amount of income tax that he or she has to pay and a tax auditor who concerns the amount. Both parties determine offers independently, denoted by $t_{i}$ and $t_{j}$, respectively. Nothing but the court can decide the right amount of tax. For simplicity, we omit the case that is partially decided in favor of the taxpayer. Let $t_{i}$ (resp. $t_{j}$ ) be the amount that a taxpayer (resp. auditor) calculated, where $0<t_{i}<t_{j}$. Furthermore, let $\theta \in\left(t_{i}, t_{j}\right)$ be a right amount of taxes.

Assume that both parties know probabilistic distribution of $\theta$, which is denoted by a continuously differentiable function $F$ associated with density function $f$. Neither of them know $\theta$ due to the complex of the tax law. Assume further that the court chooses the offer that is closer to $\theta$ : If $\theta$ $-t_{i}<t_{j}-\theta$, then the condition that $t_{i}$ is right amount is $\theta<\left(t_{i}+t_{j}\right) / 2$. On the other hand, if $\theta-t_{i}$ $>t_{j}-\theta$, then the condition that $t_{j}$ is right amount is $\theta>\left(t_{i}+t_{j}\right) / 2$. Let the expected amount of taxes be $\Phi$. Given these assumptions, this value is as follows:

$$
\Phi\left(t_{i}, t_{j}\right)=t_{i} F(\theta)+t_{j}(1-F(\theta)) .
$$

For simplicity, we assume that both parties are risk-neutral. The definitions of best responses and an equilibrium are as follows: A best response for a taxpayer to any given $t_{j}$ is strategy $t_{i}^{*}\left(t_{j}\right)$ such that $\Phi\left(t_{i}, t_{j}^{*}\right) \leq \Phi\left(t_{i}, t_{j}\right)$ for all other strategies $t_{i}$. Similarly, a best response for the tax auditor to a given strategy $t_{j}$ for a taxpayer is a strategy $t_{j}^{*}\left(t_{i}\right)$ such that $\Phi\left(t_{i}, t_{j}^{*}\right) \geq \Phi\left(t_{i}, t_{j}\right)$ for all other strategies $t_{j}$. An equilibrium, therefore, is a pair of strategies $\left(t_{i}^{*}, t_{j}^{*}\right)$ such that $t_{i}^{*}=t_{i}\left(t_{j}^{*}\right)$ and $t_{j}^{*}$ $=t_{j}\left(t_{j}^{*}\right)$. That is, a taxpayer minimizes the expected amount of taxes and a tax auditor maximizes this amount. The pair of offers $\left(t_{i}^{*}, t_{j}^{*}\right)$ is to be Nash equilibrium of the game such as $t_{i}^{*}=\arg \min _{t_{i}}$ $\Phi\left(t_{i}, t_{j}^{*}\right)$ and $t_{j}^{*}=\arg \min _{t_{j}} \Phi\left(t_{i}, t_{j}^{*}\right)$.

When the function $F$ is continuous and increasing, the necessary condition of the equilibrium implies that the average of equilibrium strategies must equal the median of these strategies and that the gap between equilibrium strategies must equal to the reciprocal value of the density function at the median of strategies. In particular, when $\theta$ is normally distributed with mean $m$ and variance $\sigma^{2}$, the median of the distribution equals the mean of the distribution. In this case, the equilibrium is $\left(t_{i}^{*}, t_{j}^{*}\right)=\left(m-\frac{\sigma \sqrt{2 \pi}}{2}, m+\frac{\sigma \sqrt{2 \pi}}{2}\right)$. It is obvious that, for all $\sigma>0, t_{j}^{*}(\sigma)-t_{i}^{*}(\sigma)$, is increasing in $\sigma$. That is, with tax law complexity, there are times when a taxpayer and an auditor do not agree on what right amount of tax is.

\section{Tax Dispute Resolution}

This section extends the analysis of the way a modification can reduce tax dispute incentives. In section 2 we noted that our explanation for a revised return is based on the fact that parties have different expectations about the outcome of a resolution. When parties try to obtain better than what they expect, the bargaining, or revised return, will be mutually beneficial.

Assuming that risk-neutral parties maximize their expected payoff, the parties engage in bargaining that results in the taxpayer making a payment $S>0$ to the tax office. If they fail to bargain, the process of tax dispute resolution and trial would ensure.

First, consider the problem of the tax office. We regard the payoff as additional tax revenue. The tax office expects the probability of winning (resp. losing) at trial with $1-F\left(\theta^{*}\right)$ (resp. $F\left(\theta^{*}\right)$ ). Then, additional tax revenue is $t^{*}=t_{j}^{*}-t_{i}^{*}$ (resp. zero), where $t^{*}$ increases in $\sigma>0$. Let $C_{j}>0$ be tax office's dispute costs. Under this concept is included a cost such as dispute term. Then, the office's expected payoff when the bargaining do not be concluded is

$$
\left(1-F\left(\theta^{*}\right)\right) t^{*}(\sigma)+F\left(\theta^{*}\right) \cdot 0-C_{j} .
$$


On the other hand, let $R_{j}>0$ be office's bargaining cost. We assume that the amount of bargaining cost is not large enough to be worth taking a trial. The expected payoff when bargaining is concluded is $S-R_{j}$. Therefore, the condition that the office accepts the payment is

$$
S>\left(1-F\left(\theta^{*}\right)\right) t^{*}(\sigma)-C_{j}+R_{j}
$$

Next, consider the taxpayer's problem. We regard his payoff as additional credit. : $t^{*}=t_{j}^{*}$ $-t_{i}^{*}$. The taxpayer expects his probability of winning (resp. losing) at trial with $F\left(\theta^{*}\right)$ (resp. 1 $-F\left(\theta^{*}\right)$ ). Then, his or her payoff when she wins (resp. loses) is $t^{*}$ (resp. zero). Let be his or her litigation costs. This cost also can be interpreted into office's litigation cost. When the bargaining is not be concluded, her expected payoff is

$$
F\left(\theta^{*}\right) t^{*}(\sigma)+\left(1-F\left(\theta^{*}\right)\right) \cdot 0-C_{i} .
$$

On the other hand, let $R_{i}>0$ be his or her bargaining cost. When the bargaining is concluded, his or her expected payoff is $t^{*}(\sigma)-S-R_{i}$. The condition that this taxpayer makes payment is

$$
S<\left(1-F\left(\theta^{*}\right)\right) t^{*}(\sigma)+C_{i}-R_{i} .
$$

Here, we assume that $C_{h}>R_{h}, h=i, j$. Then, $C_{h}-R_{h}>0$ means additional cost when bargaining does not be concluded.

Combining with equation (3) and (5), the "range" of payment (Miceli [4], ch. 8)) exists if the following condition holds :

$$
\sum_{h}\left(C_{h}-R_{h}\right)>0, h=i, j .
$$

From this result, we obtain the following proposition:

Proposition: For any $\sigma>0$, if $\sum_{h}\left(C_{h}-R_{h}\right)>0, h=i, j$, then $S>0$.

This proposition implies that, with tax law complexity and costly resolution, even though additional litigation cost is small amount, a revised return as the payment from taxpayer to tax office is sure to take place and parties avoid involvement in dispute.

\section{Conclusion}

Tax auditor is authorized to carry out criminal investigations of taxpayers suspected of intentional tax evasion. While the tax enforcement policies seek to prevent tax evasion and ensure that taxpayers pay the legal amount of tax, in practical situations, there are times when the agency and the taxpayer do not agree on what legal amount of tax is. There are two ways in which a taxpayer can object to an assessment imposed by the tax auditor, namely, administrative protest and litigation. These disagreements or tax disputes are apt to be taken with uncertainty of taxable incomes.

With Nash assumption in which rational taxpayer and auditor interact strategically, we can show that uncertainty of taxable incomes yields disagreements on what legal amount of tax is, and that the parties avoid involvement in disputes.

Here, possible payment does not necessarily mean an attempt at bribery. Indeed, in our model, tax auditor is willing to take a bribe, but he or she does not approach the taxpayer with the offer of a bribe.

Finally, we will need to be more careful that the assumption of risk neutrality makes it impossible for parties to condition the decision-making of going to law on type levels.

\section{Acknowledgment}

I appreciate helpful comments from Ken'ici Senba (Aoyama-Gakuin university), Tomoki 
Waragai (Waseda university) and participants of the Economic Analysis session at the Annual Meeting of the Japan Section of the RSAI. I have benefited from the valuable suggestions of two anonymous referees. I am responsible for any remaining errors. This research is supported by Kyushu-Sangyo university library ("Kenkyu-Tokutei Tosho" in 1996).

\section{References}

[1] Allingham, M. and A. Sandmo, "Income Tax Evasion: A Theoretical Analysis", Journal of Public Economics, 1 (1972), pp. 323-338.

[2] Andreoni, J., Erand, B. and J. Feinstein “Tax Compliance”, Journal of Economic Literature, 36 (1988), pp. 818-860

[3] Gibbons, R. "Learning in Equilibrium Models of Arbitration", American Economic Review, 78 (1988), pp. 896-912.

[4] Miceli, T.J. Economics of the Law-Torts, Contracts, Property, Litigation, Oxford University Press, 1997. 